\title{
Prediction of Clinical Response After 1 Year of Infliximab Therapy in Rheumatoid Arthritis Based on Disease Activity at 3 Months: Posthoc Analysis of the RISING Study
}

\author{
Tsutomu Takeuchi, Nobuyuki Miyasaka, Takashi Inui, Toshiro Yano, Toru Yoshinari, \\ Tohru Abe, and Takao Koike
}

ABSTRACT. Objective. To investigate the probability of clinical remission (REM) or low disease activity (LDA) after 1 year of infliximab (IFX) therapy based on disease activity at 3 months in patients with rheumatoid arthritis (RA).

Methods. Methotrexate-refractory patients with RA received $3 \mathrm{mg} / \mathrm{kg}$ of IFX at weeks 0,2 , and 6 , followed by $3 \mathrm{mg} / \mathrm{kg}, 6 \mathrm{mg} / \mathrm{kg}$, or $10 \mathrm{mg} / \mathrm{kg}$ every 8 weeks from Week 14 (W14) to Week 46 . Correlation of disease activity at W14 with disease activity at W54 and probability of REM/LDA at W54 were analyzed in each dosing group.

Results. Disease activities at W14 were significantly correlated with both disease activity at W54 and probability of REM/LDA at W54 in patients continuing $3 \mathrm{mg} / \mathrm{kg}$ as well as in those receiving 6 $\mathrm{mg} / \mathrm{kg}$ or $10 \mathrm{mg} / \mathrm{kg}$ therapy from W14. Results showed that, if approximate REM or LDA had not been achieved by W14,>50\% of patients continuing $3 \mathrm{mg} / \mathrm{kg}$ therapy would not be able to achieve REM or LDA at W54. However, even in patients with high or moderate disease activity at W14, dose escalation to $6 \mathrm{mg} / \mathrm{kg}$ or $10 \mathrm{mg} / \mathrm{kg}$ enabled many to achieve REM/LDA.

Conclusion. Disease activity at W14 in standard-dose IFX therapy enabled the prediction of longterm clinical response at continued standard dose, as well as subsequent escalated-dose regimens. Disease activity at W14 was hypothesized to be an important index for IFX treatment strategy. (First Release Feb 15 2015; J Rheumatol 2015;42:599-607; doi:10.3899/jrheum.140572)

Key Indexing Terms:

INFLIXIMAB

DISEASE ACTIVITY

\author{
RHEUMATOID ARTHRITIS \\ PREDICTION
}

\section{CLINICAL RESPONSE RISING STUDY}

From the Division of Rheumatology, Department of Internal Medicine, School of Medicine, Keio University; Graduate School of Medical and Dental Sciences, Tokyo Medical and Dental University, Tokyo; Mitsubishi Tanabe Pharma Corporation, Osaka; Saitama Medical Center, Saitama Medical University, Saitama; and the Sapporo Medical Center NTT EC, Hokkaido, Japan.

Mitsubishi Tanabe Pharma Corporation sponsored this clinical trial and was responsible for the collection and analysis of data. T. Takeuchi and T. Koike have received lecture fees from Mitsubishi Tanabe Pharma. N. Miyasaka has received grant support from Mitsubishi Tanabe Pharma. T. Inui, T. Yano, and T. Yoshinari are employees of Mitsubishi Tanabe Pharma.

T. Takeuchi, MD, PhD, Professor, Division of Rheumatology, Department of Internal Medicine, School of Medicine, Keio University; N. Miyasaka, $M D$, PhD, Professor Emeritus, Graduate School of Medical and Dental Sciences, Tokyo Medical and Dental University; T. Inui, DVM; T. Yano, PhD; T. Yoshinari, MS, Mitsubishi Tanabe Pharma Corporation; T. Abe, MD, PhD, Professor Emeritus, Saitama Medical Center, Saitama Medical University; T. Koike, $M D, P h D$, Chief Executive, Sapporo Medical Center NTT EC.

Address correspondence to Dr. T. Takeuchi, Division of Rheumatology, Department of Internal Medicine, School of Medicine, Keio University, 35 Shinanomachi, Shinjuku-ku, Tokyo 160-8582, Japan.

E-mail: tsutake@z5.keio.jp

Full Release Article. For details see Reprints/Permissions at jrheum.org Accepted for publication December 18, 2014.
Treat-to-target (T2T) strategy for rheumatoid arthritis (RA) recommends that the efficacy of the treatment regimen should be assessed after 3-6 months, with therapy adjustment (continuation, dose escalation, or alteration) subsequently evaluated based on this assessment ${ }^{1}$. These recommendations, therefore, suggest that the prediction of the longterm efficacy based on the findings in 3-6 months is necessary for treating patients with RA.

Anti-human tumor necrosis factor (TNF)- $\alpha$ antibody infliximab (IFX) has demonstrated a high efficacy against $\mathrm{RA}^{2,3,4,5,6}$; however, several reports have shown that some patients were unable to achieve clinical remission (REM) or low disease activity (LDA) - the treatment goal - despite receiving standard-dose treatment $(3 \mathrm{mg} / \mathrm{kg}$ every 8 $\left.w_{k s}\right)^{3,4,5,6}$, thereby resulting in implementing a dose-escalating regimen 7,8 .

Reports have shown that the clinical response of anti-TNF agents at 3 months can predict the probability of attaining REM or LDA at 1 year ${ }^{9,10,11}$. However, few have studied the prediction at standard-dose treatment of subsequent efficacy of escalated-dose IFX treatment. Further,

Personal non-commercial use only. The Journal of Rheumatology Copyright $@$ $~ 2015$. All rights reserved. 
how dose-adjusted IFX therapy should be performed in nonresponders of standard-dose treatment remains unclear.

We had previously reported the results of a randomized, double-blind clinical trial that showed the usefulness of dose-escalating IFX treatment in RA [Efficacy and Safety of Increased Dose of TA-650 (Infliximab) in Patients With Rheumatoid Arthritis, NCT00691028]; it was designated the RISING study (impact on radiographic and clinical response to infliximab therapy concomitant with methotrexate in patients with rheumatoid arthritis by trough serum level in a dose-escalating study) ${ }^{3}$. In our study, patients received standard-dose therapy at baseline, Week 2 (W2), and W6, followed by a standard- or escalated-dose regimen from W14, a protocol in line with "real-world" clinical practice.

We previously reported that plasma TNF- $\alpha$ levels at baseline were correlated with the clinical responses in both standard- and escalated-dose treatments of $\mathrm{IFX}^{12}$. Further, several reports have shown that serum IFX levels and anti-IFX antibodies (ATI) are correlated with clinical response to IFX therapy $3,13,14,15$. However, neither serum IFX/ATI levels nor plasma TNF- $\alpha$ levels can be measured easily in clinical settings. Therefore, some other predictive factor that can be evaluated easily in daily clinical practice is required to predict the efficacy of IFX treatment.

We performed a posthoc analysis of the RISING study to determine the clinical response assessed after 3 months of standard-dose therapy in predicting the probability of REM or LDA at 1 year in continued standard-dose as well as subsequent escalated-dose therapy.

\section{MATERIALS AND METHODS}

Study protocol. The protocol of the RISING study has been reported previously $^{3,12}$. Patients with active RA, despite MTX treatment, were treated with a standard-dose of IFX $(3 \mathrm{mg} / \mathrm{kg})$ at baseline, W2, and W6, after which they were randomized into 3 groups and treated with $3 \mathrm{mg} / \mathrm{kg}, 6$ $\mathrm{mg} / \mathrm{kg}$, or $10 \mathrm{mg} / \mathrm{kg}$ every 8 weeks from W14 to W46. Active RA was defined in our study by the presence of $\geq 6$ swollen joints, $\geq 6$ tender joints, and an erythrocyte sedimentation rate of $\geq 28 \mathrm{~mm} / \mathrm{h}$ or a serum C-reactive protein (CRP) level of $\geq 2.0 \mathrm{mg} / \mathrm{dl}$. Disease activity was evaluated by the Simplified Disease Activity Index (SDAI) or the Disease Activity Score in 28 joints, based on CRP (DAS28-CRP). Cutoff values for DAS28-CRP were as follows: REM $<2.3$; LDA $<2.7$; moderate disease activity (MDA) $\geq 2.7-\leq 4.1$; high disease activity (HDA) $>4.1^{16}$. Disease activity at W54 was evaluated using the last observation carried forward (LOCF) method. Radiographic progression was evaluated based on the change in modified total Sharp score ${ }^{17}$ from baseline to W54 ( $\Delta \mathrm{TSS}$ ), and radiographic remission was defined as $\Delta \mathrm{TSS} \leq 0.5^{18}$. Physical function was evaluated based on the Health Assessment Questionnaire (HAQ) score $^{19}$, and functional remission was defined as a HAQ score $\leq 0.5^{20}$. HAQ score at W54 was evaluated using the LOCF approach. Serum IFX level was measured using ELISA, as described ${ }^{3}$.

Association analysis of efficacies in disease activity, radiographic progression, and physical function at W54 with early disease activity. Correlations of disease activities or components of disease activity and serum IFX levels at W6 to W14 with disease activity, HAQ score, and $\Delta T S S$ at W54 were calculated using Pearson correlation coefficient or Spearman rank correlation coefficient. Multiple linear regression analysis was used to identify independent correlated factors of disease activity and
HAQ score at W54, and multiple logistic regression analysis was performed to identify independent predictors of REM/LDA achievement and functional remission at W54. In these multiple regression analyses, the explanatory variables used were IFX dosage, disease activity at W14, sex, age, disease duration, body mass index, concomitant MTX dose, duration of MTX use, concomitant use of glucocorticoid, comorbidities, concomitant use of disease-modifying antirheumatic drugs other than MTX, HAQ score at baseline, and TSS at baseline. IFX dosage and disease activity at W14 were included in all stepwise regression models, and other variables were chosen using stepwise backward selection to minimize the Bayesian information criterion.

Median effective levels (EL50) of disease activity at W14, where the probability of REM or LDA at W54 equaled 0.5 in each dosing group, were estimated by the logistic regression formula based on the disease activity at W14. The probability of REM or LDA at W54 in each dosing group was estimated using each logistic regression formula when disease activities at W14 were at the threshold level between LDA/MDA (SDAI 11 , DAS28-CRP 2.7) and between MDA/HDA (SDAI 26, DAS28-CRP 4.1). Discrimination of REM/LDA was assessed using the area under the receiver-operating curve (ROC/AUC).

Statistical analyses were performed using JMP 11.1.1 software (SAS Institute Japan Ltd.)

\section{RESULTS}

Patient background and efficacy at W54. Patient background at baseline and efficacies in disease activity, radiographic progression ( $\triangle \mathrm{TSS})$, and physical function (HAQ score) at W54 in each dosing group are shown in Table 1. Most patients exhibited HDA at baseline. Dose dependency was observed in the clinical response, and the response at $10 \mathrm{mg} / \mathrm{kg}$ was significantly higher than at 3 $\mathrm{mg} / \mathrm{kg}$. No significant improvements in $\triangle \mathrm{TSS}$ and HAQ score were observed in the $6 \mathrm{mg} / \mathrm{kg}$ or $10 \mathrm{mg} / \mathrm{kg}$ groups compared with the $3 \mathrm{mg} / \mathrm{kg}$ group.

Correlation of disease activity and components of disease activity at W14 with disease activity, physical function, and radiographic progression at W54. Table 2 shows the correlation coefficients of disease activities at W6 to W14 with disease activity, HAQ score, and $\triangle \mathrm{TSS}$ at W54. In the 3 $\mathrm{mg} / \mathrm{kg}$ and $6 \mathrm{mg} / \mathrm{kg}$ groups, SDAI value, improvement value of SDAI ( $\triangle$ SDAI), and improvement rate $(\%)$ of SDAI at W14 were significantly correlated with SDAI at W54 (p < 0.0001 ), with SDAI value at W14 showing the highest correlation. Of note, SDAI at W14 in the $10 \mathrm{mg} / \mathrm{kg}$ group also showed high correlation with SDAI at W54, with similar results found for DAS28-CRP. However, the components of SDAI or DAS28-CRP at W14 (28-tender joint count, 28-swollen joint count, CRP, patient global assessment, and physician global assessment), disease activity at W6 and W10, and serum IFX levels were also significantly correlated with disease activity at W54 (p < 0.05 ); those correlation coefficients were smaller than with disease activity at W14 (Appendix 1). In univariate linear or logistic regression analysis, no common correlated factor with disease activity and achieving REM or LDA at W54 was observed except for disease activity at W14, IFX dosage, and HAQ score at baseline (data not shown). In multiple linear or logistic regression analysis using stepwise

Personal non-commercial use only. The Journal of Rheumatology Copyright (C) 2015. All rights reserved 
Table 1. Characteristics of patients at baseline and clinical response at W54 in each dosing group. Values are mean (SD) or n (\%) unless otherwise indicated.

\begin{tabular}{|c|c|c|c|}
\hline Characteristics & $3 \mathrm{mg} / \mathrm{kg}, \mathrm{n}=99$ & $6 \mathrm{mg} / \mathrm{kg}, \mathrm{n}=104$ & $10 \mathrm{mg} / \mathrm{kg}, \mathrm{n}=104$ \\
\hline \multicolumn{4}{|l|}{ Characteristics of patients at baseline } \\
\hline Age, yrs & $49.7(11.7)$ & $48.8(11.8)$ & $50.4(12.5)$ \\
\hline Disease duration, yrs & $8.3(7.8)$ & $7.2(7.1)$ & $8.4(7.7)$ \\
\hline MTX dose, mg/week & $7.8(1.6)$ & $7.9(1.9)$ & $7.7(1.7)$ \\
\hline SDAI & $37.5(12.2)$ & $36.1(13.4)$ & $36.9(11.0)$ \\
\hline HDA (DAS28-CRP) & $96(97)$ & $99(95)$ & $100(96)$ \\
\hline HAQ score & $1.18(0.64)$ & $1.18(0.65)$ & $1.21(0.68)$ \\
\hline TSS, median (IQR) $)^{\dagger}$ & $28.0(9.0-77.5)$ & $32.2(12.0-62.4)$ & $38.3(11.0-73.8)$ \\
\hline \multicolumn{4}{|l|}{ Clinical response at W54 } \\
\hline SDAI & $13.8(14.0)$ & $11.8(13.6)$ & $10.1(11.5)^{*}$ \\
\hline LDA (SDAI) & $56(57)$ & $67(64)$ & $72(69) *$ \\
\hline HAQ & $0.70(0.67)$ & $0.61(0.69)$ & $0.61(0.62)$ \\
\hline Functional remission, $\mathrm{HAQ} \leq 0.50$ & $50(51)$ & $66(63)$ & $60(58)$ \\
\hline$\Delta \mathrm{TSS}, \mathrm{W} 0-\mathrm{W} 54$, median $(\mathrm{IQR})^{\ddagger}$ & $0.0(-1.0-1.0)$ & $0.5(-0.5-1.6)$ & $0.0(-1.0-0.8)$ \\
\hline Radiographic remission, $\Delta \mathrm{TSS} \leq 0.5^{\ddagger}$ & $63(73)$ & $54(59)$ & $70(74)$ \\
\hline
\end{tabular}

Cutoff values for DAS28-CRP: REM $<2.3, \mathrm{LDA}<2.7$, MDA $\geq 2.7-\leq 4.1$, and HDA $>4.1^{16} .{ }^{\dagger} \mathrm{n}=98$ and $\mathrm{n}=103 \mathrm{in}$ the $3 \mathrm{mg} / \mathrm{kg}$ and $6 \mathrm{mg} / \mathrm{kg}$ groups, respectively. $* \mathrm{p}<0.05$ versus $3 \mathrm{mg} / \mathrm{kg}$ group (ANCOVA or logistic regression analysis using the clinical response at W10 as a covariant). ${ }^{\ddagger} \mathrm{n}=86,92$, and 95 in the $3 \mathrm{mg} / \mathrm{kg}, 6 \mathrm{mg} / \mathrm{kg}$, and $10 \mathrm{mg} / \mathrm{kg}$ groups, respectively. W54: Week 54; MTX: methotrexate; SDAI: Simplified Disease Activity Index; HDA: high disease activity; DAS28-CRP: 28-joint Disease Activity Score-C-reactive protein; HAQ: Health Assessment Questionnaire; TSS: total Sharp score; IQR: interquartile range; LDA: low disease activity; REM: clinical remission; $\triangle$ TSS: change in modified TSS; MDA: moderate disease activity.

selection procedure, only disease activity at W14 and IFX dosage were identified as the common independent correlated factors (Table 3).

Radiographic progression at W54 ( $\Delta \mathrm{TSS})$ showed little significant correlation with disease activity at W14 in each dosing group (Table 2), and achievement of radiographic remission had similar results (data not shown). Meanwhile, HAQ score at W54 significantly correlated with disease activity at W14 in each dosing group (Table 2), and functional remission at W54 had similar results (data not shown). In multiple linear or logistic regression analysis, disease activity at W14 as well as the HAQ score at baseline and disease duration (or duration of MTX use) were identified as independent factors correlated with the HAQ score or functional remission at W54 (Table 3).

Probability of REM/LDA at W54 based on disease activity at W14. Because disease activity at W14 and IFX dosage were the only independent factors correlated with disease activity at W54, probability of REM/LDA at W54 in each dosing group was calculated by logistic regression analysis using disease activity at W14 (Figure 1, Figure 2, and Figure 3).

EL50 values (95\% CI) of SDAI at W14 for the $3 \mathrm{mg} / \mathrm{kg}$, $6 \mathrm{mg} / \mathrm{kg}$, and $10 \mathrm{mg} / \mathrm{kg}$ groups to achieve REM (SDAI) at W54, estimated using each logistic regression formula, were $4.4(-1.1-7.0), 8.0(4.4-11)$, and $7.9(2.0-11)$, respectively, and the ROC/AUC $(95 \% \mathrm{CI})$ were calculated as 0.84
(0.74-0.91), $0.86(0.76-0.92)$, and $0.80(0.69-0.87)$, respectively. Values for LDA (SDAI) were 18 (13-24), 22 (17-28), and 28 (22-41), respectively [ROC/AUC (95\% CI) 0.78 $(0.68-0.86), 0.82(0.72-0.89)$, and $0.76(0.65-0.84)]$. In contrast, the values of DAS28-CRP at W14 for the $3 \mathrm{mg} / \mathrm{kg}$, $6 \mathrm{mg} / \mathrm{kg}$, and $10 \mathrm{mg} / \mathrm{kg}$ groups to achieve REM (DAS28-CRP) at W54 were 2.4 (1.4-2.9), 3.0 (2.6-3.3), and 3.4 (2.8-3.9), respectively [ROC/AUC $(95 \%$ CI) 0.79 (0.68-0.87), 0.87 (0.79-0.93), and $0.79(0.69-0.87)]$, while those for LDA (DAS28-CRP) were 3.0 (2.5-3.5), 3.4 (3.0-3.8), and 3.9 (3.3-4.5), respectively [ROC/AUC (95\% CI) $\quad 0.80 \quad(0.69-0.87), \quad 0.86 \quad(0.78-0.92)$, and 0.78 $(0.67-0.85)]$. In patients in which SDAI at W14 was 11.0 (threshold between LDA/MDA), probability of REM (SDAI) in the $3 \mathrm{mg} / \mathrm{kg}, 6 \mathrm{mg} / \mathrm{kg}$, and $10 \mathrm{mg} / \mathrm{kg}$ groups was estimated as $19 \%, 37 \%$, and $40 \%$, respectively, while that for LDA was $67 \%, 78 \%$, and $79 \%$, respectively. However, in patients in which SDAI at W14 was 26.0 (threshold between MDA/HDA), probability of REM (SDAI) in the 3 $\mathrm{mg} / \mathrm{kg}, 6 \mathrm{mg} / \mathrm{kg}$, and $10 \mathrm{mg} / \mathrm{kg}$ groups was estimated as $0.9 \%, 4 \%$, and $8 \%$, respectively, while that for LDA was $30 \%, 37 \%$, and $54 \%$, respectively. Meanwhile, in patients whose DAS28-CRP at W14 was 2.7 (threshold between LDA/MDA), probability of REM (DAS28-CRP) in the 3 $\mathrm{mg} / \mathrm{kg}, 6 \mathrm{mg} / \mathrm{kg}$, and $10 \mathrm{mg} / \mathrm{kg}$ groups was estimated as $42 \%, 59 \%$, and $66 \%$, respectively, while that for LDA was

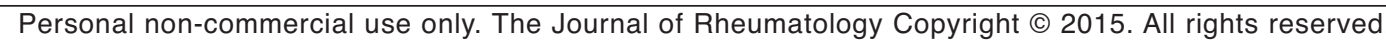


Table 2. Correlation coefficient of disease activity at W6, W10, or W14 with disease activity, HAQ score, and $\Delta$ TSS at W54.

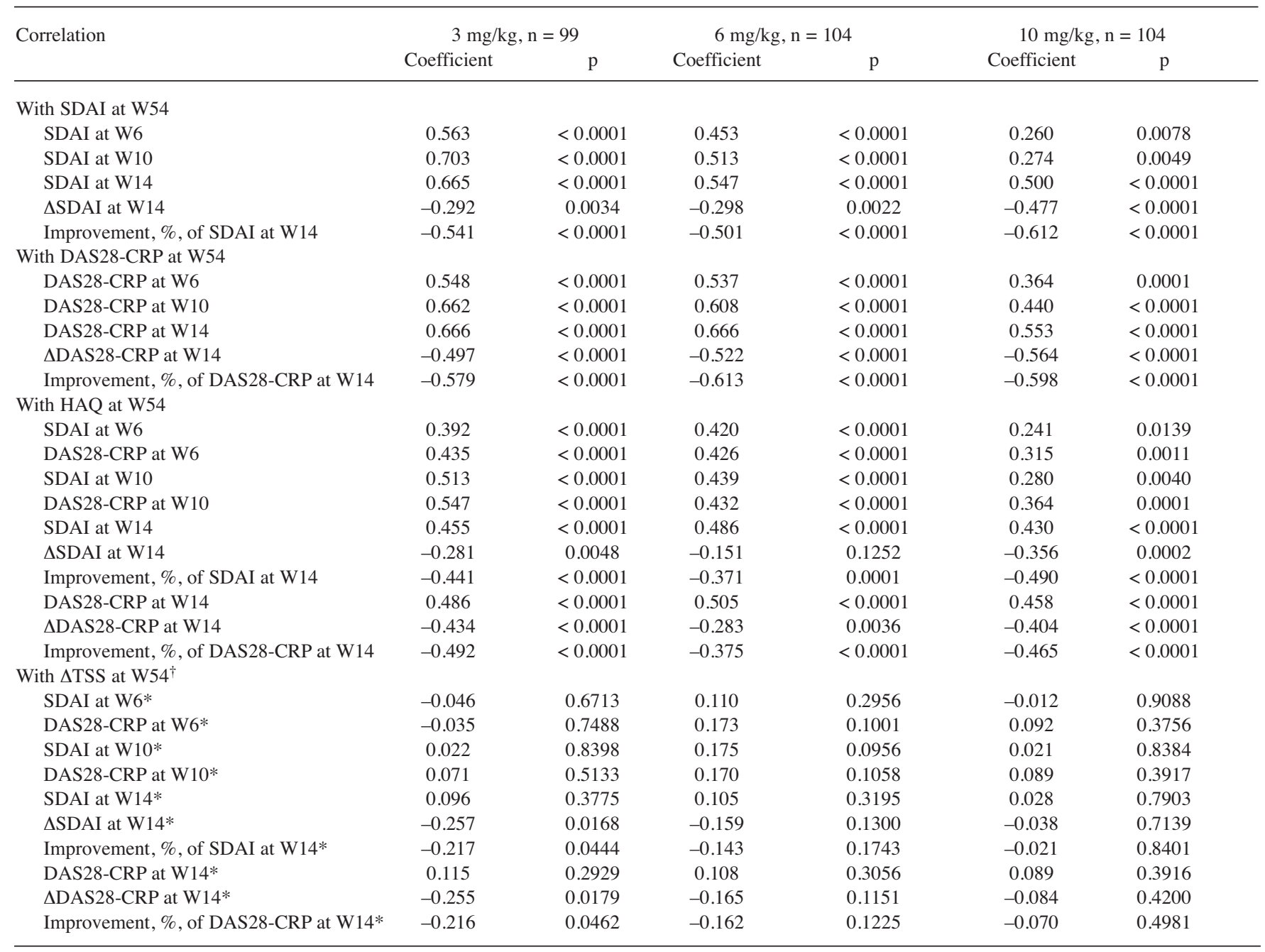

Coefficients and $\mathrm{p}$ values were evaluated using Pearson correlation coefficient or $*$ Spearman rank correlation coefficient. ${ }^{\dagger} \mathrm{n}=86,92$, and 95 in the $3 \mathrm{mg} / \mathrm{kg}$, $6 \mathrm{mg} / \mathrm{kg}$, and $10 \mathrm{mg} / \mathrm{kg}$ groups, respectively. W6: Week 6; W10: Week 10; W14: Week 14; HAQ: Health Assessment Questionnaire; $\Delta$ TSS: change in modified total Sharp score; W54: Week 54; SDAI: Simplified Disease Activity Index; $\triangle$ SDAI: improvement value of SDAI; DAS28-CRP: 28-joint Disease Activity Score-C-reactive protein; $\triangle \mathrm{DAS} 28$-CRP: improvement value of DAS28-CRP.

$59 \%, 72 \%$, and $73 \%$, respectively. However, in patients whose DAS28-CRP at W14 was 4.1 (threshold between MDA/HDA), probability of REM (DAS28-CRP) in the 3 $\mathrm{mg} / \mathrm{kg}, 6 \mathrm{mg} / \mathrm{kg}$, and $10 \mathrm{mg} / \mathrm{kg}$ groups was estimated as $16 \%, 15 \%$, and $33 \%$, respectively, while that for LDA was $25 \%, 29 \%$, and $45 \%$, respectively.

Similar logistic curves were obtained when achievement of REM/LDA at W54 was evaluated using nonresponse imputation methods (patients who dropped out for any reason were defined as nonresponders) in each dosing group (data not shown).

\section{DISCUSSION}

While the approved dose of IFX for RA treatment ranges from standard dose ( $3 \mathrm{mg} / \mathrm{kg}$ every $8 \mathrm{wks})$ to $6-10 \mathrm{mg} / \mathrm{kg}$ every 4 weeks ( 4.0 -fold to 6.7 -fold $)-$ a dosing range wider than that found with other anti-TNF agents (typically 2-fold or less) - findings on the usefulness of IFX dose escalation have been disputed. Although higher-dose or dose-escalating treatment did not show statistically better efficacy than standard-dose treatment in several clinical trials ${ }^{2,4,5,21}$, nonresponders at standard-dose treatment have been reported to respond to early dose-escalating treatment ${ }^{13,22}$.

Similarly, in the RISING study, dose escalation from W14 improved clinical response over continued standard-dose treatment, notably in patients with nonresponse at $\mathrm{W} 10^{3}$. Additionally, in our study, rates of REM and LDA in DAS28-CRP at 1 year in the $3 \mathrm{mg} / \mathrm{kg}$ group were $10 \%$ and $13 \%$, respectively, while those in the $10 \mathrm{mg} / \mathrm{kg}$ group were $21 \%$ and $29 \%$, respectively (data not shown), in patients with HDA at W14 despite receiving a standard-dose treatment. If these patients are considered failures for 
Table 3. Independent-associated factors with disease activity, REM/LDA, HAQ score, and functional remission at W54.

Table 3A. Multiple linear regression analysis of SDAI, DAS28-CRP, and HAQ score at W54.

\begin{tabular}{|c|c|c|c|c|}
\hline Factors & B & $95 \% \mathrm{CI}$ & $\beta$ & $\mathrm{p}$ \\
\hline \multicolumn{5}{|l|}{ SDAI at $\mathrm{W} 54, \mathrm{R}^{2}=0.3365$} \\
\hline Constant & 5.813 & $2.502-9.124$ & 0 & 0.0006 \\
\hline SDAI at W14 & 0.606 & $0.508-0.704$ & 0.569 & $<0.0001$ \\
\hline \multicolumn{5}{|c|}{ DAS28-CRP at W54, $\mathrm{R}^{2}=0.4114$} \\
\hline Constant & 1.047 & $0.578-1.517$ & 0 & $<0.0001$ \\
\hline \multicolumn{5}{|l|}{ HAQ at $W 54, R^{2}=0.3683$} \\
\hline Constant & -0.091 & $-0.281-0.099$ & 0 & 0.3483 \\
\hline IFX dosage, $\mathrm{mg} / \mathrm{kg}$ & -0.015 & $-0.035-0.006$ & -0.063 & 0.1671 \\
\hline HAQ at WO & 0.353 & $0.253-0.452$ & 0.351 & $<0.0001$ \\
\hline Disease duration, yrs & 0.014 & $0.006-0.022$ & 0.160 & 0.0008 \\
\hline SDAI at W14 & 0.019 & $0.013-0.024$ & 0.345 & $<0.0001$ \\
\hline Disease duration, yrs & 0.014 & $0.006-0.022$ & 0.161 & 0.0006 \\
\hline DAS28-CRP at W14 & 0.175 & $0.129-0.221$ & 0.369 & $<0.0001$ \\
\hline
\end{tabular}

Table 3B. Multiple logistic regression analysis of achievement of REM/LDA and functional remission at W54.

\begin{tabular}{|c|c|c|c|}
\hline \multicolumn{4}{|c|}{ REM (SDAI) at W54, $* \mathrm{R}^{2}=0.3911$} \\
\hline IFX dosage, $\mathrm{mg} / \mathrm{kg}$ & 1.127 & $1.017-1.251$ & 0.0218 \\
\hline SDAI at W14 & 0.843 & $0.800-0.882$ & $<0.0001$ \\
\hline \multicolumn{4}{|c|}{ LDA (SDAI) at W54, $* \mathrm{R}^{2}=0.3087$} \\
\hline IFX dosage, $\mathrm{mg} / \mathrm{kg}$ & 1.118 & $1.018-1.232$ & 0.0195 \\
\hline IFX dosage, $\mathrm{mg} / \mathrm{kg}$ & 1.156 & $1.050-1.277$ & 0.0031 \\
\hline DAS28-CRP at W14 & 0.325 & $0.241-0.424$ & $<0.0001$ \\
\hline \multicolumn{4}{|c|}{ LDA (DAS28-CRP) at W54, $* \mathrm{R}^{2}=0.3757$} \\
\hline IFX dosage, $\mathrm{mg} / \mathrm{kg}$ & 1.123 & $1.023-1.235$ & 0.0143 \\
\hline DAS28-CRP at W14 & 0.347 & $0.264-0.445$ & $<0.0001$ \\
\hline \multicolumn{4}{|c|}{ Functional remission at W54, $* \mathrm{R}^{2}=0.3805$} \\
\hline IFX dosage, $\mathrm{mg} / \mathrm{kg}$ & 1.078 & $0.980-1.188$ & 0.1238 \\
\hline Duration of MTX use, yrs & 0.880 & $0.791-0.973$ & 0.0125 \\
\hline HAQ at W0 & 0.241 & $0.145-0.387$ & $<0.0001$ \\
\hline DAS28-CRP at W14 & 0.506 & $0.395-0.637$ & $<0.0001$ \\
\hline
\end{tabular}

Independent variables were selected using a backward stepwise procedure. Functional remission was defined as HAQ $\leq 0.50$. * Nagelkerke $\mathrm{R}^{2}$. REM: clinical remission; LDA: low disease activity; HAQ: Health Assessment Questionnaire; W54: Week 54; SDAI: Simplified Disease Activity Index; DAS28-CRP: 28-joint Disease Activity Score-C-reactive protein; B: nonstandardized coefficients; $\beta$ : standardized coefficients; $\mathrm{R}^{2}$ : explained variance; IFX: infliximab; W14: Week 14; W0: Week 0; MTX: methotrexate.

anti-TNF agents, this clinical response might not be inferior to those switched to other biologics ${ }^{23,24,25}$. Accordingly, early dose escalation of IFX is useful in patients with inadequate response to standard-dose therapy and the prediction of efficacy of standard- and escalated-dose treatment is extremely important for the strategy of IFX treatment.

In our analysis, disease activity at W14 was most highly correlated with that at W54, and no other independent

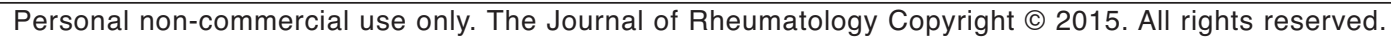



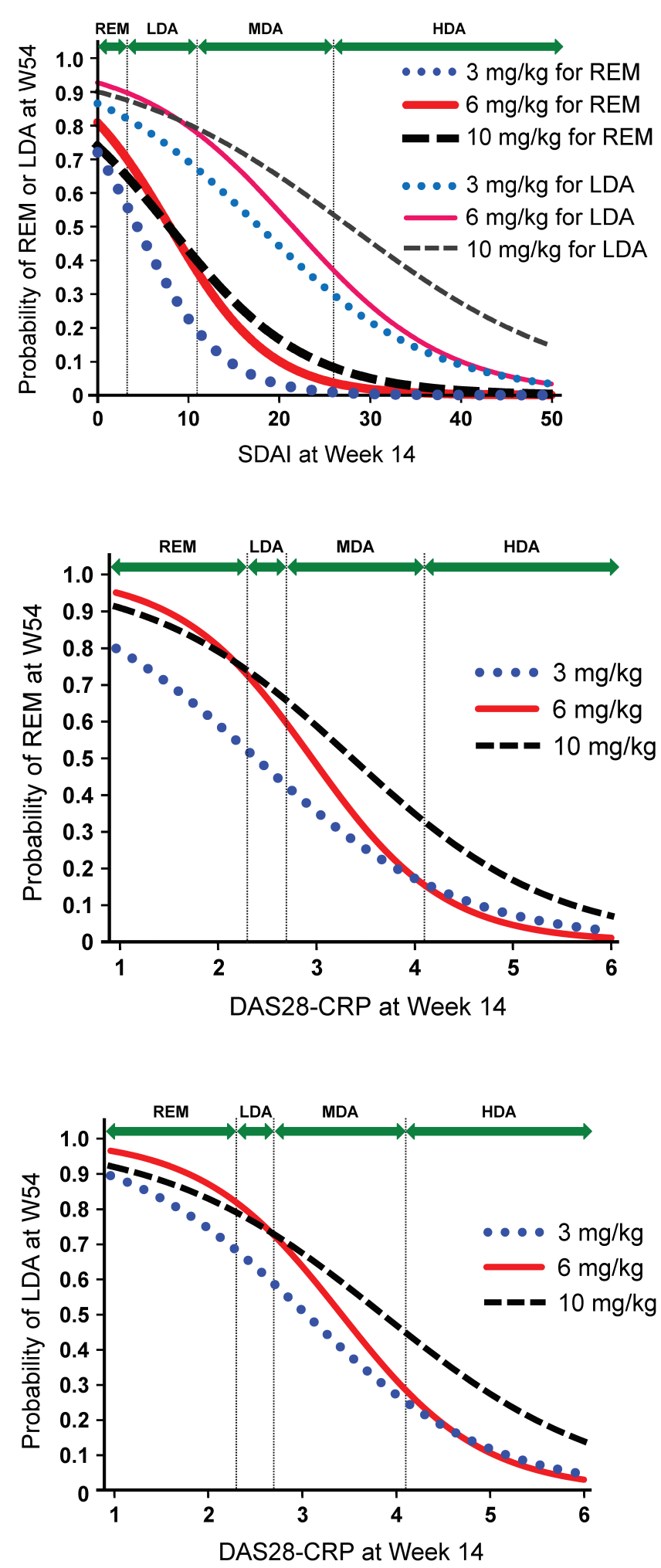

factors were noted except IFX dosage; therefore, disease activity at W14 most accurately predicted the clinical response at W54 in each dosing group. Our results indicated that the probability of treatment goal achievement in each
Figure 1. Probability of REM or LDA at W54 based on SDAI at W14. REM: clinical remission; LDA: low disease activity; W54: Week 54; SDAI: Simplified Disease Activity Index; W14: Week 14.

Figure 2. Probability of REM at W54 based on DAS28-CRP at W14. Cutoff values for DAS28-CRP were as follows: REM $<2.3$; LDA $<2.7$; MDA $\geq 2.7-\leq 4.1$; HDA $>4.1^{16}$. REM: clinical remission; W54: Week 54; DAS28-CRP: 28-joint Disease Activity Score-C-reactive protein; W14: Week 14; LDA: low disease activity; MDA: moderate disease activity; HDA: high disease activity.

Figure 3. Probability of LDA at W54 based on DAS28-CRP at W14. Cutoff values for DAS28-CRP were as follows: REM $<2.3$; LDA $<2.7$; MDA $\geq 2.7-\leq 4.1$; HDA $>4.1^{16}$. LDA: low disease activity; W54: Week 54; DAS28-CRP: 28-joint Disease Activity Score-C-reactive protein; W14: Week 14; REM: clinical remission; MDA: moderate disease activity; HDA: high disease activity.

dosing group can be predicted from the logistic curve created using REM/LDA at W54 as an objective variable and disease activity at W14 as an explanatory variable (Figures 1, 2, and 3). For example, when DAS28-CRP at 
W14 is 2.4 (about the threshold between REM/LDA), we may predict that REM will not be achieved in $50 \%$ of patients at W54, even after 1 year of $3 \mathrm{mg} / \mathrm{kg}$ treatment. However, if disease activity at W14 is 3.0 (MDA), increasing IFX dose after W14 may induce REM in more than half of patients. Figures 1, 2, and 3 further suggest that when DAS28-CRP at W14 was improved to 2.7 (threshold between LDA/MDA), clinical responses to the $6 \mathrm{mg} / \mathrm{kg}$ and $10 \mathrm{mg} / \mathrm{kg}$ treatments were almost equivalent, and while an increase in dosage may be necessary in some patients, an increase of up to $10 \mathrm{mg} / \mathrm{kg}$ may not be required. However, if DAS28-CRP at W14 is 4.1 (threshold between MDA/HDA), an increase to $6 \mathrm{mg}$ will likely not markedly improve clinical response, but an increase to $10 \mathrm{mg} / \mathrm{kg}$ may increase the probability of REM/LDA. Given the above, Figures 1, 2, and 3, which show the probability of REM/LDA in individual patients with various disease activities at W14, are important indices for personalizing IFX dosage, including continuation of standard-dose therapy, dose escalation, or switching to another therapy. Meanwhile, disease activity at W10 was also useful in predicting the probability of REM/LDA at W54, despite showing a lower correlation coefficient with disease activity at W54 than at W14. Despite the lower correlation, making an early decision at W10 for dose escalation might be advantageous in clinical settings.

Disease activity at W14 showed little correlation with $\Delta$ TSS values or radiographic remission in each dosing group. Radiographic progression in our present study was insufficient in accurately predicting radiographic remission. In addition, it was reported that radiographic progression was disassociated with disease activity ${ }^{26}$, and that the $\Delta$ TSS value at W54 was low even in patients who showed an HDA at W14 of IFX treatment ${ }^{27}$. Accordingly, we concluded that disease activity at W14 was not useful for predicting radiographic progression with IFX treatment. Of note, the HAQ score and the functional remission at W54 were closely correlated with disease activity at W14. However, other independent correlated factors, such as the HAQ score at baseline and disease duration, were also identified, as well as disease activity at W14 (Table 3). Accordingly, functional remission might not be accurately predicted using only disease activity at W14.

Several limitations to our present study warrant mention. First, the correlation coefficients between disease activities at W14 and W54 ranged from 0.5 to 0.7 . Although no other independent correlated factors were found, clinical response at W54 could not be fully explained by the disease activity at W14 alone. Second, in most subjects in our study, disease activities at baseline were HDA. Thus, the adaptability of analysis results in cases when initial activity was otherwise (e.g., MDA or extremely high disease activity) was unknown. Third, our analysis was based on disease activity at W54, and the adaptability of our findings in predicting clinical response thereafter was also unknown.

However, despite these limitations, our results will prove useful in devising at least a 1-year strategy for IFX treatment. Our findings also prove that IFX treatment in line with a T2T strategy will help prevent the progression of RA. The cost-effectiveness of IFX dose escalation will be discussed in future studies.

\section{ACKNOWLEDGMENT}

We thank all of the investigators who participated in the RISING study.

\section{REFERENCES}

1. Smolen JS, Landewé R, Breedveld FC, Buch M, Burmester G, Dougados M, et al. EULAR recommendations for the management of rheumatoid arthritis with synthetic and biological disease-modifying antirheumatic drugs: 2013 update. Ann Rheum Dis 2014;73:492-509.

2. Lipsky PE, van der Heijde DM, St Clair EW, Furst DE, Breedveld FC, Kalden JR, et al. Infliximab and methotrexate in the treatment of rheumatoid arthritis. Anti-Tumor Necrosis Factor Trial in Rheumatoid Arthritis with Concomitant Therapy Study Group. N Engl J Med 2000;343:1594-602.

3. Takeuchi T, Miyasaka N, Inoue K, Abe T, Koike T; RISING study. Impact of trough serum level on radiographic and clinical response to infliximab plus methotrexate in patients with rheumatoid arthritis: results from the RISING study. Mod Rheumatol 2009;19:478-87.

4. St Clair EW, van der Heijde DM, Smolen JS, Maini RN, Bathon JM, Emery P, et al. Combination of infliximab and methotrexate therapy for early rheumatoid arthritis: a randomized, controlled trial. Arthritis Rheum 2004;50:3432-43.

5. Westhovens R, Yocum D, Han J, Berman A, Strusberg I, Geusens P, et al. The safety of infliximab, combined with background treatments, among patients with rheumatoid arthritis and various comorbidities: a large, randomized, placebo-controlled trial. Arthritis Rheum 2006;54:1075-86.

6. Nam JL, Winthrop KL, van Vollenhoven RF, Pavelka K, Valesini G, Hensor EM, et al. Current evidence for the management of rheumatoid arthritis with biological disease-modifying antirheumatic drugs: a systematic literature review informing the EULAR recommendations for the management of RA. Ann Rheum Dis 2010;69:976-86.

7. Yazici Y, Krasnokutsky S, Barnes JP, Hines PL, Wang J, Rosenblatt L. Changing patterns of tumor necrosis factor inhibitor use in 9074 patients with rheumatoid arthritis. J Rheumatol 2009;36:907-13.

8. Bolge SC, Carter CT, Mueller CS, Bailey RA, Ingham MP. Comparative multidatabase analysis of dosing patterns and infusion intervals for the first 12 infliximab infusions in patients with rheumatoid arthritis. Clin Ther 2012;34:2286-92.

9. Aletaha D, Funovits J, Keystone EC, Smolen JS. Disease activity early in the course of treatment predicts response to therapy after one year in rheumatoid arthritis patients. Arthritis Rheum 2007;56:3226-35

10. Curtis JR, Luijtens K, Kavanaugh A. Predicting future response to certolizumab pegol in rheumatoid arthritis patients: features at 12 weeks associated with low disease activity at 1 year. Arthritis Care Res 2012;64:658-67.

11. Dougados MR, van der Heijde DM, Brault Y, Koenig AS, Logeart IS. When to adjust therapy in patients with rheumatoid arthritis after initiation of etanercept plus methotrexate or methotrexate alone: findings from a randomized study (COMET). J Rheumatol 2014;41:1922-34

Personal non-commercial use only. The Journal of Rheumatology Copyright @ $\subset$ 2015. All rights reserved. 
12. Takeuchi T, Miyasaka N, Tatsuki Y, Yano T, Yoshinari T, Abe T, et al. Baseline tumour necrosis factor alpha levels predict the necessity for dose escalation of infliximab therapy in patients with rheumatoid arthritis. Ann Rheum Dis 2011;70:1208-15.

13. Rahman MU, Strusberg I, Geusens P, Berman A, Yocum D, Baker $\mathrm{D}$, et al. Double-blinded infliximab dose escalation in patients with rheumatoid arthritis. Ann Rheum Dis 2007;66:1233-8.

14. St Clair EW, Wagner CL, Fasanmade AA, Wang B, Schaible T, Kavanaugh A, et al. The relationship of serum infliximab concentrations to clinical improvement in rheumatoid arthritis: results from ATTRACT, a multicenter, randomized, double-blind, placebo-controlled trial. Arthritis Rheum 2002;46:1451-9.

15. van Schouwenburg PA, Rispens T, Wolbink GJ. Immunogenicity of anti-TNF biologic therapies for rheumatoid arthritis. Nat Rev Rheumatol 2013;9:164-72.

16. Inoue E, Yamanaka H, Hara M, Tomatsu T, Kamatani N. Comparison of disease activity score (DAS)28- erythrocyte sedimentation rate and DAS28- C-reactive protein threshold values. Ann Rheum Dis 2007;66:407-9.

17. Sharp JT, Lidsky MD, Collins LC, Moreland J. Methods of scoring the progression of radiologic changes in rheumatoid arthritis. Correlation of radiologic, clinical and laboratory abnormalities. Arthritis Rheum 1971;14:706-20.

18. van Tuyl LH, Felson DT, Wells G, Smolen J, Zhang B, Boers M; American College of Rheumatology; European League against Rheumatism Committee to Define Remission for Clinical Trials. Evidence for predictive validity of remission on long-term outcome in rheumatoid arthritis: a systematic review. Arthritis Care Res 2010;62:108-17.

19. Fries JF, Spitz PW, Kraines RG, Holman HR. Measurement of patient outcome in arthritis. Arthritis Rheum 1980;23:137-45.

20. Felson DT, Smolen JS, Wells G, Zhang B, van Tuyl LH, Funovitis $\mathrm{J}$, et al. American College of Rheumatology/European League Against Rheumatism provisional definition of remission in rheumatoid arthritis for clinical trial. Ann Rheum Dis 2011; 70:404-13.
21. Pavelka K, Jarosová K, Suchý D, Senolt L, Chroust K, Dusek L, et al. Increasing the infliximab dose in rheumatoid arthritis patients: a randomised, double blind study failed to confirm its efficacy. Ann Rheum Dis 2009;68:1285-9.

22. van der Bijl AE, Goekoop-Ruiterman YP, de Vries-Bouwstra JK, ten Wolde S, Han KH, van Krugten MV, et al. Infliximab and methotrexate as induction therapy in patients with early rheumatoid arthritis. Arthritis Rheum 2007;56:2129-34.

23. Genovese MC, Becker JC, Schiff M, Luggen M, Sherrer Y, Kremer $\mathrm{J}$, et al. Abatacept for rheumatoid arthritis refractory to tumor necrosis factor alpha inhibition. N Engl J Med 2005;353:1114-23.

24. Cohen SB, Emery P, Greenwald MW, Dougados M, Furie RA, Genovese MC, et al. Rituximab for rheumatoid arthritis refractory to anti-tumor necrosis factor therapy: results of a multicenter, randomized, double-blind, placebo-controlled, phase III trial evaluating primary efficacy and safety at twenty-four weeks. Arthritis Rheum 2006;54:2793-806.

25. Smolen JS, Kay J, Doyle MK, Landewé R, Matteson EL, Wollenhaupt J, et al. Golimumab in patients with active rheumatoid arthritis after treatment with tumour necrosis factor alpha inhibitors (GO-AFTER study): a multicentre, randomised, double-blind, placebo-controlled, phase III trial. Lancet 2009;374:210-21.

26. Smolen JS, Han C, Bala M, Maini RN, Kalden JR, van der Heijde $\mathrm{D}$, et al. Evidence of radiographic benefit of treatment with infliximab plus methotrexate in rheumatoid arthritis patients who had no clinical improvement: a detailed subanalysis of data from the anti-tumor necrosis factor trial in rheumatoid arthritis with concomitant therapy study. Arthritis Rheum 2005;52:1020-30.

27. Smolen JS, Han C, van der Heijde DM, Emery P, Bathon JM, Keystone E, et al; Active-Controlled Study of Patients Receiving Infliximab for the Treatment of Rheumatoid Arthritis of Early Onset (ASPIRE) Study Group. Radiographic changes in rheumatoid arthritis patients attaining different disease activity states with methotrexate monotherapy and infliximab plus methotrexate: the impacts of remission and tumour necrosis factor blockade. Ann Rheum Dis 2009;68:823-7. 
APPENDIX 1. Correlation coefficient of components disease activity at W14 and serum IFX level at W6 to W14 with disease activity, HAQ score, and $\triangle \mathrm{TSS}$ at W54.

\begin{tabular}{|c|c|c|c|c|c|c|}
\hline \multirow[t]{2}{*}{ Correlation } & \multicolumn{2}{|c|}{$3 \mathrm{mg} / \mathrm{kg}, \mathrm{n}=99$} & \multicolumn{2}{|c|}{$6 \mathrm{mg} / \mathrm{kg}, \mathrm{n}=104$} & \multicolumn{2}{|c|}{$10 \mathrm{mg} / \mathrm{kg}, \mathrm{n}=104$} \\
\hline & Coefficient & $\mathrm{p}$ & Coefficient & $\mathrm{p}$ & Coefficient & $\mathrm{p}$ \\
\hline \multicolumn{7}{|l|}{ With SDAI at W54 } \\
\hline SJC28 at W14 & 0.465 & $<0.0001$ & 0.420 & $<0.0001$ & 0.278 & 0.0042 \\
\hline CRP at W14 & 0.475 & $<0.0001$ & 0.385 & $<0.0001$ & 0.378 & $<0.0001$ \\
\hline PtGA at W14 & 0.486 & $<0.0001$ & 0.526 & $<0.0001$ & 0.394 & $<0.0001$ \\
\hline Serum IFX level at W10*广 & -0.313 & 0.0016 & -0.449 & $<0.0001$ & -0.365 & 0.0002 \\
\hline Serum IFX level at W14* & -0.246 & 0.0142 & -0.448 & $<0.0001$ & -0.385 & $<0.0001$ \\
\hline \multicolumn{7}{|l|}{ With DAS28-CRP at W54 } \\
\hline TJC28 at W14 & 0.568 & $<0.0001$ & 0.454 & $<0.0001$ & 0.404 & $<0.0001$ \\
\hline SJC28 at W14 & 0.425 & $<0.0001$ & 0.475 & $<0.0001$ & 0.238 & 0.0151 \\
\hline $\mathrm{CRP}$ at $\mathrm{W} 14$ & 0.475 & $<0.0001$ & 0.456 & $<0.0001$ & 0.389 & $<0.0001$ \\
\hline Serum IFX level at W14* & -0.297 & 0.0028 & -0.484 & $<0.0001$ & -0.432 & $<0.0001$ \\
\hline \multicolumn{7}{|l|}{ With HAQ at W54 } \\
\hline TJC28 at W14 & 0.362 & 0.0002 & 0.370 & 0.0001 & 0.420 & $<0.0001$ \\
\hline SJC28 at W14 & 0.277 & 0.0055 & 0.316 & 0.0011 & 0.145 & 0.1411 \\
\hline CRP at W14 & 0.255 & 0.0109 & 0.302 & 0.0018 & 0.251 & 0.0100 \\
\hline PtGA at W14 & 0.501 & $<0.0001$ & 0.573 & $<0.0001$ & 0.354 & 0.0002 \\
\hline PGA at W14 & 0.397 & $<0.0001$ & 0.503 & $<0.0001$ & 0.365 & 0.0001 \\
\hline Serum IFX level at W6* & -0.062 & 0.5400 & -0.106 & 0.2849 & -0.213 & 0.0298 \\
\hline Serum IFX level at W10 ${ }^{* \dagger}$ & -0.180 & 0.0744 & -0.183 & 0.0626 & -0.243 & 0.0135 \\
\hline Serum IFX level at W14* & -0.117 & 0.2474 & -0.177 & 0.0723 & -0.280 & 0.0039 \\
\hline \multicolumn{7}{|l|}{ With $\Delta$ TSS at W54 } \\
\hline TJC28 at W14* & -0.052 & 0.6320 & 0.053 & 0.6150 & 0.013 & 0.8975 \\
\hline
\end{tabular}

Correlations of components of disease activity at W14 and serum IFX levels at W6 to W14 with disease activity, HAQ score and $\Delta$ TSS at W54 were calculated using Pearson correlation coefficient or *Spearman rank correlation coefficient. ${ }^{\dagger} \mathrm{n}=103$ in $10 \mathrm{mg} / \mathrm{kg}$ group. ${ }^{\ddagger} \mathrm{n}=86,92$, and 95 in 3,6 , and $10 \mathrm{mg} / \mathrm{kg}$ groups, respectively. W14: Week 14; IFX: infliximab; W6: Week 6; HAQ: Health Assessment Questionnaire; $\Delta$ TSS: change in total modified Sharp score; W54: Week 54; SDAI: Simplified Disease Activity Index; TJC28: tender joint count in 28 joints; SJC28: swollen joint count in 28 joints; CRP: C-reactive protein; PtGA: patient's global assessment; PGA: physician's global assessment; W10: Week 10; DAS28: 28-joint Disease Activity Score. 


\section{Correction}

Prediction of Clinical Response After 1 Year of Infliximab

Therapy in Rheumatoid Arthritis Based on Disease Activity at 3 Months: Posthoc Analysis of the RISING Study*

Takeuchi T, Miyasaka N, Inui T, Yano T, Yoshinari T, Abe T, et al. Prediction of clinical response after 1 year of infliximab therapy in rheumatoid arthritis based on disease activity at 3 months: posthoc analysis of the RISING study. J Rheumatol 2015;42:599-607. In Table 3A, column 1 was incorrectly indented. The corrected table appears here. We regret the error. *This correction is to the First Release version only, published online February 15, 2015. doi:10.3899/jrheum.140572.C1

Table 3. Independent-associated factors with disease activity, REM/LDA, HAQ score, and functional remission at W54.

Table 3A. Multiple linear regression analysis of SDAI, DAS28-CRP, and HAQ score at W54.

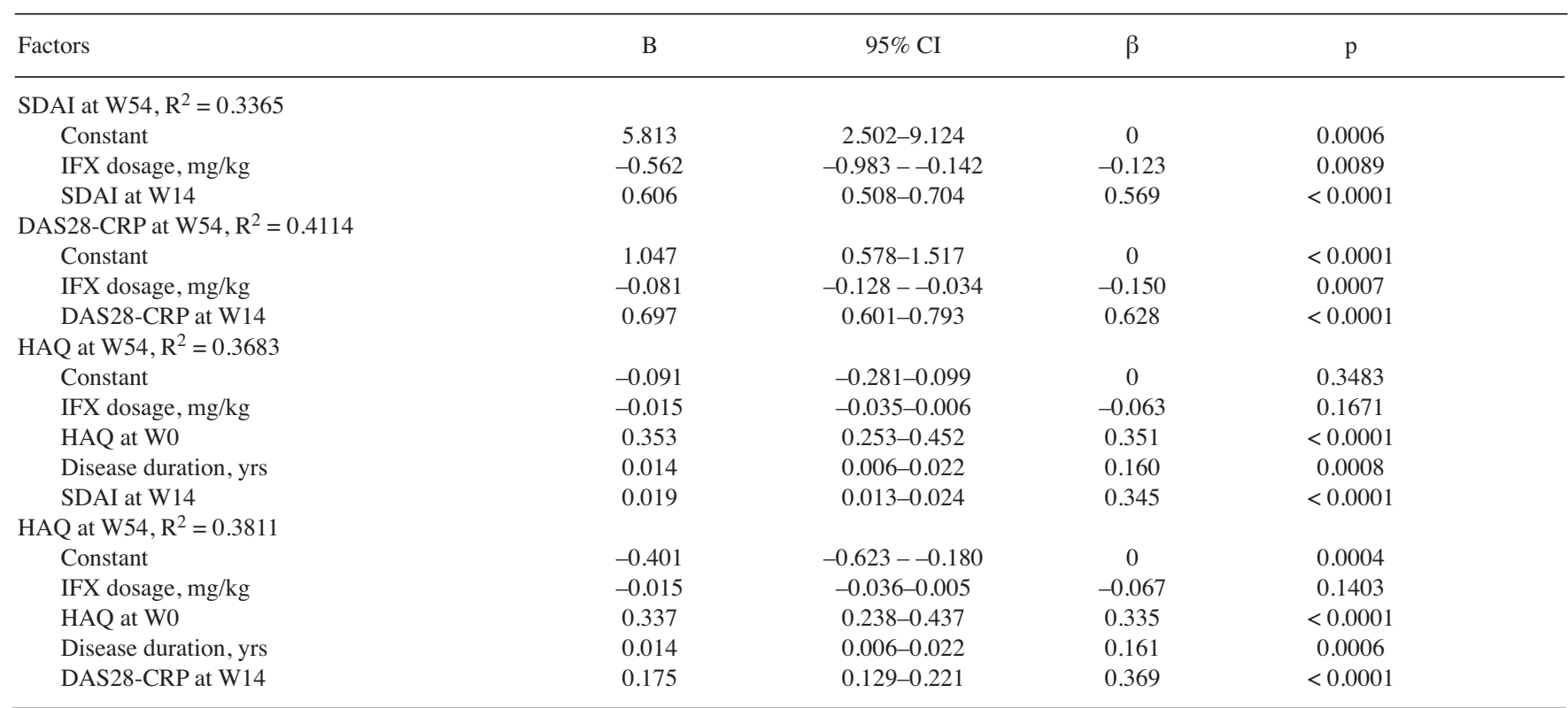

Table 3B. Multiple logistic regression analysis of achievement of REM/LDA and functional remission at W54.

\begin{tabular}{|c|c|c|c|}
\hline Factors & OR & $95 \% \mathrm{CI}$ & $\mathrm{p}$ \\
\hline \multicolumn{4}{|c|}{$\mathrm{REM}(\mathrm{SDAI})$ at $\mathrm{W} 54,{ }^{*} \mathrm{R}^{2}=0.3911$} \\
\hline IFX dosage, $\mathrm{mg} / \mathrm{kg}$ & 1.127 & $1.017-1.251$ & 0.0218 \\
\hline SDAI at W14 & 0.843 & $0.800-0.882$ & $<0.0001$ \\
\hline \multicolumn{4}{|c|}{$\mathrm{LDA}(\mathrm{SDAI})$ at $\mathrm{W} 54,{ }^{*} \mathrm{R}^{2}=0.3087$} \\
\hline IFX dosage, $\mathrm{mg} / \mathrm{kg}$ & 1.118 & $1.018-1.232$ & 0.0195 \\
\hline IFX dosage, $\mathrm{mg} / \mathrm{kg}$ & 1.156 & $1.050-1.277$ & 0.0031 \\
\hline DAS28-CRP at W14 & 0.325 & $0.241-0.424$ & $<0.0001$ \\
\hline \multicolumn{4}{|c|}{ LDA (DAS28-CRP) at W54, $* \mathrm{R}^{2}=0.3757$} \\
\hline IFX dosage, $\mathrm{mg} / \mathrm{kg}$ & 1.123 & $1.023-1.235$ & 0.0143 \\
\hline DAS28-CRP at W14 & 0.347 & $0.264-0.445$ & $<0.0001$ \\
\hline \multicolumn{4}{|c|}{ Functional remission at W54, $* \mathrm{R}^{2}=0.3805$} \\
\hline Duration of MTX use, yrs & 0.880 & $0.791-0.973$ & 0.0125 \\
\hline HAQ at W0 & 0.241 & $0.145-0.387$ & $<0.0001$ \\
\hline DAS28-CRP at W14 & 0.506 & $0.395-0.637$ & $<0.0001$ \\
\hline
\end{tabular}

Independent variables were selected using a backward stepwise procedure. Functional remission was defined as HAQ $\leq 0.50$. * Nagelkerke $\mathrm{R}^{2}$. REM: clinical remission; LDA: low disease activity; HAQ: Health Assessment Questionnaire; W54: Week 54; SDAI: Simplified Disease Activity Index; DAS28-CRP: 28-joint Disease Activity Score-C-reactive protein; B: nonstandardized coefficients; $\beta$ : standardized coefficients; $\mathrm{R}^{2}$ : explained variance; IFX: infliximab; W14: Week 14; W0: Week 0; MTX: methotrexate. 